\title{
Four-year mortality by some socioeconomic indicators: the Oslo study
}

\author{
I. HOLME, A. HELGELAND, I. HJERMANN, P. LEREN, AND P. G. LUND-LARSEN \\ From the Life Insurance Companies' Institute for Medical Statistics and the Medical Outpatient Clinic, Ullevaal \\ Hospital, Oslo
}

SUMMARY The association between four-year mortality and some socioeconomic indicators has been studied in all Oslo men aged 40-49, invited to a screening programme for cardiovascular disease, and in a 'healthy' subgroup of participating men free of cardiovascular disease and diabetes at screening. The lowest social class exhibited a much higher total mortality than the other classes. This was pronounced for a variety of causes of death, such as cancer of the lung, accidents and homicide, and coronary heart disease. The negative mortality gradient by increasing socioeconomic status can to a certain degree be 'explained' by the coronary risk factor pattern.

In recent years, it has become more evident that persons in lower socioeconomic classes exhibit a higher morbidity and mortality from coronary heart disease (CHD) and sudden death (SD) than those in the middle and upper classes. ${ }^{1-3}$ It is also known that several coronary risk factors, such as elevated levels of serum cholesterol, serum triglycerides, blood pressure, cigarette smoking, and physical inactivity at leisure, are more prevalent in the lower classes. ${ }^{4}$

In this paper we present the four-year total and CHD + SD mortality of the Oslo study in various socioeconomic classes, and discuss to what extent some conventional risk factors might explain differences in mortality patterns between different social groups.

\section{Material and methods}

\section{SCREENING DATA}

During the period May 1972 to December 1973 a screening programme for cardiovascular disease was completed for about 16200 Oslo men aged 40-49. A number of coronary risk factors (CRF) were measured, such as serum cholesterol and triglycerides, blood pressure, and so on. A questionnaire on previous cardiovascular disease and diabetes, smoking habits, and degree of physical activity at work and at leisure was also completed. Based on previous cardiovascular studies in Oslo, ${ }^{5} \dot{6}$ three subscores of risk were computed. The subscore for serum cholesterol ranged from 1 to 24 , the one for systolic blood pressure from 1 to $4 \cdot 5$, and the one for number of cigarettes smoked daily from 1 to 4 . Finally, a coronary risk score was defined as the multiple of the three subscores. For each attending man such a coronary risk score was computed, based on the levels of the three risk factors mentioned.

A subgroup of the attending men were free of $\&$ cardiovascular disease or diabetes at screening, and they were called 'healthy' men. Further details have previously been published. ${ }^{7}$

\section{CENSUS AND MORTALITY DATA}

In the 1970 census, education is grouped into five levels, and so is the 1972 income data. ${ }^{4}$ Official codes of occupation only have been used. ${ }^{8}$ The screening data were matched with the census, income, and mortality data by means of the individual personal numbers, which completely identify each living person in Norway. All invited men $(\sim 26000)$ were followed up from date of screening until 31 December 1977 with respect to cause-specific mortality. The main diagnosis only was used as cause of death.

\section{COMPUTATIONAL METHODS}

The number of men who died in the four years of follow-up per thousand at risk was used as a crude measure of mortality. Adjustments to the mortality rates for factors other than socioeconomic status (SES) were made one at a time by the indirect method. ${ }^{9}$ Adjustments for serum cholesterol and systolic blood pressure were not made because of their relatively poor association with SES. ${ }^{4}$

By means of a cross-tabulation of income and education (Figure) five classes of socioeconomic status were defined, which is a slight modification from that previously reported. ${ }^{4}$ Class III was made 
larger and more logical. Because of small numbers, results from the two highest Social Classes (I and II) were combined.

Socioeconomic status class III is heterogeneous and was divided into three subgroups:

(i) Men with rather high education and low income, called 'under achievers'.

(ii) Men with medium education and medium income, called 'middle achievers'.

(iii) Men with rather low education and high income, called 'over achievers'.

STATISTICS

Differences between rates were tested by $\chi^{2}$ tests. Many of the hypotheses are not formulated $a$ priori, and the given significance levels may thus be artefacts and should be interpreted with care.

\section{Results}

\section{ALL INVITED MEN}

Table 1 gives numbers of deaths and rates for total and for CHD + SD mortality in relation to income and education. A systematic decrease in total and CHD + SD mortality is observed with increasing educational level. The rates for 'high' educated men are only about $50 \%$ of those for the 'low' educated. The mortality gradients by income are less systematic. The lowest income group has an especially high total mortality compared with the other groups; CHD + SD mortality does not differ greatly.

Table 2 presents death rates by social classes as defined in the Figure. There is a distinct decreasing

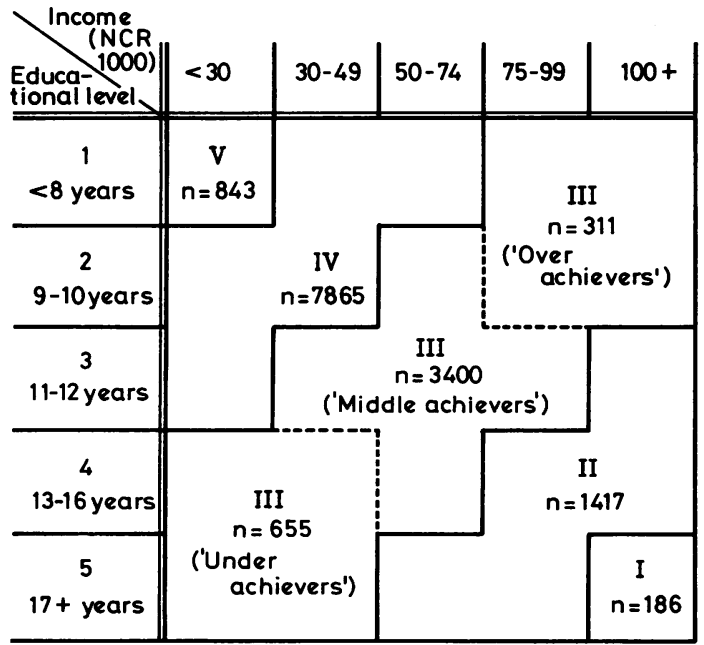

Figure Definition of social classes (I-V) by income and education.

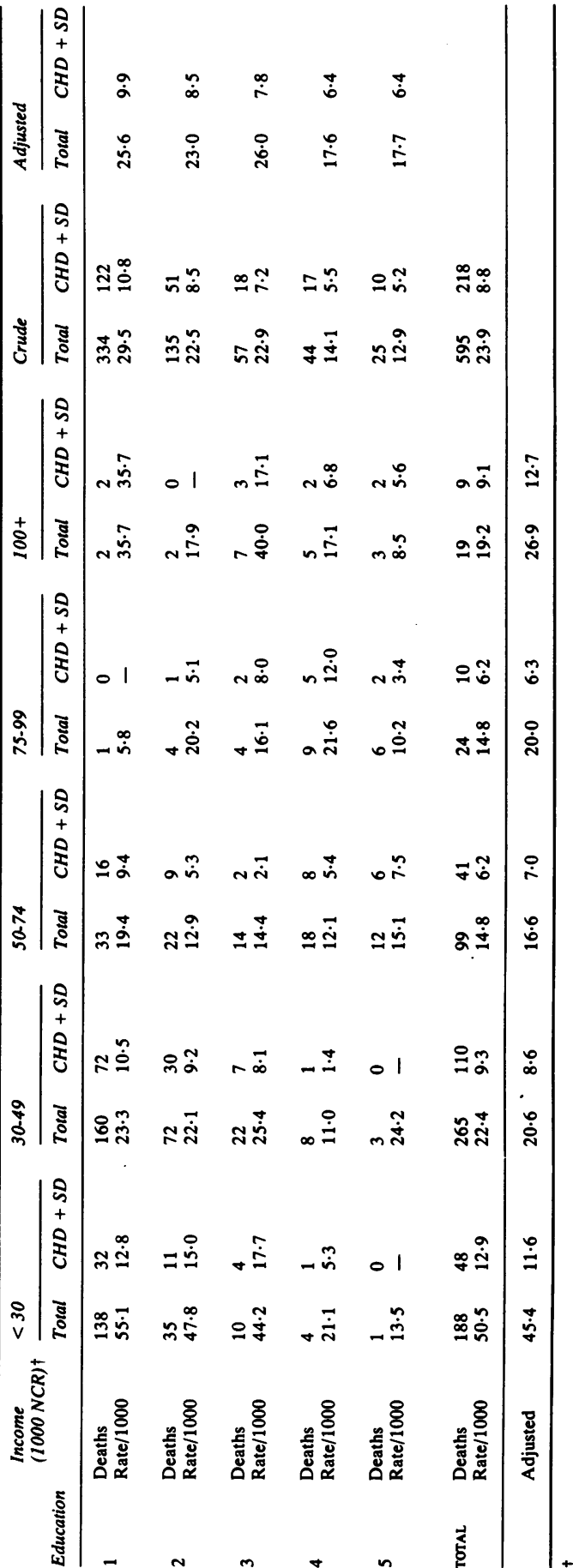

Table 1 Four-year total and CHD $+S D$ mortality rates per thousand by income and education (all invited men, aged 40-49 at entry, $n=24851$ ) 
Table 2 Total and CHD $+S D$ mortality rates per thousand by social class (all invited men, aged 40-49 at entry)

\begin{tabular}{|c|c|c|c|c|c|c|c|c|c|c|}
\hline \multirow[b]{2}{*}{ Mortality } & \multirow{2}{*}{ Social Class } & \multirow{2}{*}{$\begin{array}{l}I \\
354\end{array}$} & \multirow{2}{*}{$\begin{array}{l}I I \\
2270\end{array}$} & \multicolumn{4}{|c|}{$I I I$} & \multirow{2}{*}{$\begin{array}{l}I V . \\
12785\end{array}$} & \multirow{2}{*}{$\begin{array}{l}V \\
2504\end{array}$} & \multirow{2}{*}{$\begin{array}{l}\text { Total } \\
24851\end{array}$} \\
\hline & & & & $\begin{array}{l}\text { Under } \\
\text { achievers } \\
1115\end{array}$ & $\begin{array}{l}\text { Middle } \\
\text { achievers } \\
5286\end{array}$ & $\begin{array}{l}\text { Over } \\
\text { achievers } \\
537\end{array}$ & $\begin{array}{l}\text { Subtotal } \\
6938\end{array}$ & & & \\
\hline \multirow[t]{2}{*}{ TOTAL } & $\begin{array}{l}\text { Deaths } \\
\text { Rate/1000 }\end{array}$ & $\begin{array}{l}3 \\
8 \cdot 5\end{array}$ & $\begin{array}{l}39 \\
17 \cdot 2\end{array}$ & $\begin{array}{l}16 \\
14 \cdot 3\end{array}$ & $\begin{array}{l}80 \\
15 \cdot 1\end{array}$ & $\begin{array}{l}9 \\
16.8\end{array}$ & $\begin{array}{l}105 \\
15 \cdot 1\end{array}$ & $\begin{array}{l}310 \\
24 \cdot 2\end{array}$ & $\begin{array}{l}138 \\
55 \cdot 1\end{array}$ & $\begin{array}{l}595 \\
23.9\end{array}$ \\
\hline & & \multicolumn{2}{|c|}{$16 \cdot 0$} & & & & & & & \\
\hline \multirow[t]{3}{*}{ CHD + SD } & Deaths & 2 & 18 & 2 & 28 & 3 & 33 & 133 & 32 & 218 \\
\hline & Rate/1000 & $5 \cdot 6$ & 7.9 & $1 \cdot 8$ & $5 \cdot 3$ & $5 \cdot 6$ & $4 \cdot 8$ & $11 \cdot 0$ & $12 \cdot 8$ & $8 \cdot 8$ \\
\hline & & \multicolumn{2}{|c|}{$7 \cdot 6$} & & & & & & & \\
\hline
\end{tabular}

mortality gradient by increasing status. Social Class V especially has more than $100 \%$ higher total mortality than classes I-IV $(P<0 \cdot 01)$. CHD + SD mortality rates show the same trend $(P<0.05)$. There is a tendency towards higher mortality in over achievers compared with under achievers. The differences, however, are not significant $(P>0 \cdot 10)$.

\section{'HEALTHY' MEN}

This group consists of men free of known cardiovascular disease and diabetes at screening $(n=14815)$. Table 3 shows their total and CHD + SD death rates by socioeconomic status in crude and adjusted rates for both cigarette smoking and risk score. The unadjusted total mortality rate decreases with increasing socioeconomic status, but the gradient is dominated by class $\mathrm{V}$, which has a highly unfavourable prognosis compared with the other classes. After adjusting for the known differences in either cigarette smoking or coronary risk score based on serum cholesterol, systolic blood pressure, and cigarette smoking, ${ }^{4}$ it becomes even more evident that class $\mathrm{V}$ has an especially high death rate compared with the other classes. Class III has the lowest death rate. The ratio between the class $\mathrm{V}$ and the class I + II total death rate is reduced by $30 \%$ after adjusting for coronary risk score. For CHD के $+\mathrm{SD}$ a similar pattern is observed, and the ratio is $\overrightarrow{0}$ then reduced by $40 \%$. Thus, neither the high $\overrightarrow{\vec{\omega}}$ mortality in class V nor the low mortality in class III $\vec{\omega}$ can be wholly explained either by cigarette smoking or by coronary risk score.

Table 4 presents total and CHD + SD mortality in various occupational groups. Transport and $\stackrel{\oplus}{.}$ communication workers, especially bus, tram, and taxi drivers, have higher mortality rates than othe groups. Construction and iron and metal worke also have excess mortality for healthy ment Executives, scientists, clerks, salesmen, etc., presen with low mortality figures.

\section{Discussion}

One reason why a man has a low income may be that he is chronically ill or disabled. Such persons will probably have a substantial excess mortality. ${ }^{10}$ Thus, the observed high total mortality in the lowest $\stackrel{\square}{\square}$ income group may be a result of such a selection, and $\overrightarrow{\vec{A}}$ if adjustment is made for educational level, there is no difference between the four other income groups either in total or in CHD + SD mortality (Table 1).

Table 3 Total and CHD + SD mortality rates per thousand by socioeconomic class: crude and adjusted rates for risk score and cigarette smoking ('healthy' men, aged 40-49 at entry)

\begin{tabular}{|c|c|c|c|c|c|c|c|}
\hline \multirow[b]{2}{*}{ Mortality } & & \multicolumn{6}{|c|}{ Socioeconomic classes } \\
\hline & & $\begin{array}{l}I \\
186\end{array}$ & $\begin{array}{l}I I \\
1417\end{array}$ & $\begin{array}{l}I I I \\
4366\end{array}$ & $\begin{array}{l}I V \\
7865\end{array}$ & $\begin{array}{l}V \\
843\end{array}$ & $\begin{array}{l}\text { Total } \\
14677\end{array}$ \\
\hline \multirow[t]{2}{*}{ TOTAL } & Deaths & 1 & 13 & 30 & 105 & 26 & 175 \\
\hline & $\begin{array}{l}\text { Rates } / 1000 \\
\quad \text { adjusted (score) } \\
\text { adjusted (cigarettes) }\end{array}$ & & & $\begin{array}{l}6.9 \\
7.5 \\
7.6\end{array}$ & $\begin{array}{l}13 \cdot 4 \\
12 \cdot 6 \\
12 \cdot 6\end{array}$ & $\begin{array}{l}30 \cdot 9 \\
25 \cdot 8 \\
26 \cdot 2\end{array}$ & 11.9 \\
\hline \multirow[t]{2}{*}{$\mathrm{CHD}+\mathrm{SD}$} & Deaths & 1 & 6 & 10 & 41 & 10 & 68 \\
\hline & $\begin{array}{l}\text { Rates } / 1000 \\
\quad \text { adjusted (score) } \\
\text { adjusted (cigarettes) }\end{array}$ & & & $\begin{array}{l}2 \cdot 3 \\
2 \cdot 5 \\
2 \cdot 6\end{array}$ & $\begin{array}{l}5 \cdot 2 \\
4 \cdot 9 \\
5 \cdot 0\end{array}$ & $\begin{array}{r}11 \cdot 9 \\
9.5 \\
9.9\end{array}$ & $4 \cdot 6$ \\
\hline
\end{tabular}


Table 4 Total and CHD +SD mortality rates per thousand for selected occupational groups (healthy and all invited men aged 40-49)

\begin{tabular}{|c|c|c|c|c|}
\hline \multirow[b]{2}{*}{ Occupation } & \multicolumn{2}{|c|}{$\begin{array}{l}\text { Healthy men } \\
n=14.677\end{array}$} & \multicolumn{2}{|c|}{$\begin{array}{l}\text { All invited men } \\
n=25.779\end{array}$} \\
\hline & Total & $C H D+S D$ & Total & $C H D+S D$ \\
\hline Technical, physical science, humanistic, artistic & $8 \cdot 1$ & $2 \cdot 8$ & $27 \cdot 9$ & $8 \cdot 0$ \\
\hline Administrative, executive, managerial & $9 \cdot 4$ & $2 \cdot 9$ & $16 \cdot 8$ & $6 \cdot 1$ \\
\hline Clerical and sales & 8.9 & $2 \cdot 5$ & $18 \cdot 2$ & $8 \cdot 1$ \\
\hline Transport and communications & $19 \cdot 1$ & 9.9 & $32 \cdot 1$ & $14 \cdot 7$ \\
\hline Bus, tram, and taxi drivers & 22.9 & $15 \cdot 3$ & 31.4 & $22 \cdot 5$ \\
\hline Manufacturing and construction & $16 \cdot 0$ & $6 \cdot 2$ & $28 \cdot 2$ & 9.8 \\
\hline Services & $13 \cdot 3$ & $4 \cdot 5$ & $30 \cdot 4$ & $9 \cdot 6$ \\
\hline ALL OCCUPATIONS & $12 \cdot 2$ & $4 \cdot 6$ & $25 \cdot 6$ & $9 \cdot 2$ \\
\hline
\end{tabular}

Educational standards are established long before the age of 40 , and should be less affected by disease than income. In fact, the educational gradient of mortality is more stable, and even when adjusted for income, there is a steady declining mortality trend by increasing educational level (Table 1). It seems that of the two factors defining socioeconomic status, educational level is on the whole the most important with regard to mortality.

Compared with Social Classes I-IV, Social Class V is characterised by excess mortality from accidents and homicide (ratio $=2 \cdot 9)$, stroke (ratio $=2 \cdot 9$ ), and cancer of the lung (ratio $=2 \cdot 5$ ), whereas the excess mortality from coronary heart disease including sudden death is moderate (ratio $=1 \cdot 5)$. Total cancer mortality is also higher in Social Class V compared with the others (ratio $=1 \cdot 9$ ). Thus, the high mortality in Social Class $\mathrm{V}$ is related to a variety of causes of death. None of the data seem to contradict the assumption that low income is often caused by disease. Thus, the especially high mortality in Social Class V may be partly due to an excess morbidity at the time of screening.

It is believed that among the screening participants (about $65 \%$ of the whole cohort), the prevalence of various diseases was lower than for all invited men. Bedridden or seriously sick persons would not, of course, have attended the screening programme. Men with cardiovascular disease and diabetes have a clear excess mortality from CHD + SD and they have been excluded from those participating, securing a rather 'healthy' group with respect to CHD. Still, the socioeconomic gradient is present for CHD + SD mortality, but Social Class $V$ has an especially high total, as well as CHD + SD mortality. It is known that in the present study also the conventional risk factors such as high levels of serum cholesterol and blood pressure, cigarette smoking, and inactivity at leisure are more pronounced in Social Class V than in the other classes. ${ }^{4}$

Nevertheless, after adjustment for coronary risk score, $60 \%$ of the difference in CHD + SD mortality between Social Class V and I + II remains 'unexplained'. However, coronary risk score (based on cholesterol, systolic blood pressure, and cigarettes) hardly gives an optimal prediction of future CHD + SD. A number of other risk factors are not included in the adjustment calculations. Thus, it is believed that a great part of the socioeconomic gradient for both total and CHD + SD mortality may be 'explained' by the conventional risk factors. So much of the difference in mortality may be traced back to differences in those characteristics of life style which cause differences in coronary risk factor levels.

Social Class III has an especially favourable prognosis due to an especially low mortality rate from CHD + SD. The CHD + SD mortality rate is lower than that of the combined Social Classes I + II + IV $(P<0.01)$. This is hardly explained by the conventional risk factors, ${ }^{4}$ and other explanations must be considered. Data from England and Wales also show irregularities for Social Class III. ${ }^{2}$ This class consists to a large extent of clerks and persons in sales work. These occupations, representing about $20 \%$ of the 'healthy' group, have a low CHD + SD mortality compared with their coronary risk score. ${ }^{8}$ However, this was not found in another Norwegian study on mortality and occupation ${ }^{11}$ which on the whole showed a low correlation to our findings (data not given).

The reason why Oslo men in these occupational groups have a reasonable $\mathrm{CHD}$ prognosis is uncertain. It may be a spurious finding based on a rather small number of deaths, and should be followed with special concern in the future.

The high total and CHD + SD mortality rate of taxi and bus drivers is a well known observation ${ }^{12}$ and can partly be explained by their relatively high coronary risk score. ${ }^{8}$ Metal and iron workers also have higher CHD + SD mortality than indicated by their coronary risk score, but again this finding is not consistent with a previous report. ${ }^{11}$

Reprints from Dr. I. Holme, the Life Insurance Companies' Institute for Medical Statistics at the Oslo City Hospitals, Ulleval sykehus, Oslo, Norway. 


\section{References}

${ }^{1}$ Antonovsky A. Social class and the major cardiovascular diseases. J Chronic Dis 1968; 21: 65-106.

${ }^{2}$ Marmot MG, Adelstein AM, Robinson N, Rose GA. Changing social class distribution of heart disease. $\mathrm{Br}$ Med J 1978; 2: 1109-1112.

${ }^{3}$ Shekele RB, Ostfeld AM, Paul O. Social status and incidence of coronary heart disease. J Chronic Dis 1969; 22: 381-94.

4holme I, Helgeland A, Hjermann I, Leren P, Lund-Larsen PG. Coronary risk factors and socioeconomic status. Lancet 1976; 2: 1396-98.

${ }^{5}$ Natvig H, Borchgrevink CF, Dedichen J, Owren PA, Schiøtz EH, Westlund K. A controlled trial of the effect of linolenic acid on incidence of coronary heart disease. Scand J Clin Lab Invest 1968; 22 Suppl 105: 1-20.

- Westlund K, Nicolaysen R. Ten-year mortality and morbidity related to serum cholesterol. Scand J Clin Lab Invest 1972; 30 Suppl 127: 1-24.
${ }^{7}$ Leren P, Askevold EM, Foss OP et al. The Oslo Study. Cardiovascular disease in middle-aged and young Oslo men. Acta Med Scand (Suppl) 1976; 588: 1-38.

${ }^{8}$ Holme I, Helgeland A, Hjermann I, Leren P, Lund-Larsen PG. Coronary risk factors in various occupational groups: the Oslo Study.Br J Prev Soc Med 1977; 31: 96-100.

${ }^{\circ}$ Fleiss FL. Statistical Methods for Rates and Proportions. New York: Wiley, 1973.

${ }^{10}$ Holme I, Waaler HT. Five-year mortality in the city of Bergen, Norway, according to age, sex, and blood pressure. Acta Med Scand 1976; 200: 229-39.

${ }^{11}$ Central Bureau of Statistics of Norway. Occupational Mortality 1970-73. Statistical Handbook No. 21. Oslo: Central Bureau of Statistics, 1976.

${ }^{12}$ Morris JN, Heady JA, Raffle PAB, Roberts CG, Parks JW. Coronary heart disease and physical activity of work. Lancet 1953; 2: 1053-57. 